\title{
Expression of Plasma Prekallikrein mR NA in Human Nonhepatic Tissues and Cell Lineages Suggests Special Local Functions of the Enzyme
}

\author{
Andrea Hermanna, Marianne Arnhold, \\ Hans Kresse, Peter Neth and Edwin Fink* \\ Abteilung für Klinische Chemie und Klinische Biochemie \\ in der Chirurgischen Klinik und Poliklinik, \\ Klinikum Innenstadt, Ludwig-Maximilians-Universität, \\ Nußbaumstr. 20, D-80336 München, Germany \\ * Corresponding author
}

\begin{abstract}
At present it is generally accepted that plasma prekallikrein (PPK) is synthesized in the liver and secreted into the bloodstream. Surprisingly, it has recently been shown that PPK mRNA is present also in RNA from the kidney, adrenal gland and placenta. In spite of its novelty and possible important physiological implications this finding has been neglected. Here we report that PPK $\mathrm{mRNA}$ is expressed also in the human brain, heart, lung, trachea, endothelial cells and leukocytes as well as in a variety of fibroblast and epithelial cell lines. Expression of PPK mRNA in fibroblasts, endothelial cells and leukocytes suggests that PPK mRNA detected in RNA preparations from whole tissue may originate solely from these ubiquitously occurring cells. However, PPK mRNA expression in various epithelial cell lines demonstrates that tissue-specific cells also transcribe the PPK gene. The presence of PPK mRNA in nonhepatic tissues and cells indicates that they have the capacity to synthesize the protein. The physiological role of PPK synthesized in extrahepatic tissue is unknown. It may participate in local actions within tissues as well as contributing to the PPK pool in blood plasma. Cultured cells will provide a valuable model for exploring the physiological significance of extrahepatic PPK expression.

Key words: Contact activation / Kallikrein-kinin system / Plasma kallikrein / Reverse transcription PCR / RT-PCR.
\end{abstract}

\section{Introduction}

Plasma prekallikrein (PPK), the zymogen of the serine proteinase plasma kallikrein (PK; EC 3.4.21.34) is synthesized in hepatocytes and secreted into the blood stream (Bhoola et al., 1992). Its concentration in plasma is about $50 \mathrm{mg} / \mathrm{lof}$

\footnotetext{
a Present address: november AG, Ulrich-Schalk-Str. 3a, D-91056 Erlangen, Germany
}

which seventy five percent is complexed with high molecular weight kininogen (HK). The active enzyme is generated in the contact system, the early phase of the intrinsic pathway of blood coagulation. The contact system is activated when plasma is exposed to negatively charged surfaces: the PPK-HK complex is bound via cationic regions of domain 5 of HK to the anionic surface (Mandle et al., 1976), and activated factor XII (FXIla) generates plasma kallikrein which in turn produces FXIla (Mandle and Kaplan, 1977). Thus, by a positive feed back reaction, a local increase in the concentration of both PK and FXIla is achieved.

The two proteinases, PK and FXIla, generated during contact activation can be involved in a number of subsequent processes. Both enzymes can activate granulocytes (Schapira et al., 1982, 1983; van der Graaf et al., 1982; Wachtfogel et al., 1983, 1986) and the complement system (Ghebrehiwet et al., 1981, 1983; DiS cipio, 1982) FXIla activates factor XI and in this manner triggers the intrinsic blood coagulation cascade. PK is an efficient activator of urokinase-type plasminogen activator precursor and thus provides a link to the fibrinolysis system (Ichinose et al., 1986; Hauert et al., 1989). Probably the second most important function of PK, next to its participation in the contact activation system, is its action as a kinin-liberating enzyme in the kallikrein-kinin system (Bhoola et al., 1992).

Recently, Ciechanowicz et al. (1993) and our group (Hermann et al., 1996) found by reverse transcription PCR that PPK mRNA is present in RNA preparations from whole tissues of kidney, adrenal gland and placenta. Thus, in contrast to the generally accepted concept that plasma kallikrein is synthesized solely in the liver, one has to conclude that synthesis of PPK also takes place outside the liver and that the enzyme may have special, hitherto unknown local function(s). The surprising new finding of extrahepatic PPK mRNA synthesis and its potential importance with respect to functions of PPK/PK have obviously been overlooked, since no subsequent work on these topics has been reported.

The previous results (Ciechanowicz et al., 1993; Hermann et al., 1996) did not indicate whether PPK mRNA is expressed by ubiquitous cells like fibroblasts, endothelial cells, and white blood cells, or by tissue-specific cells. Therefore, in order to clarify this issue and to find a model system for investigating the physiological significance of extrahepatic PPK synthesis, we undertook a study on PPK mRNA expression in cultured human fibroblasts and epithelial cells originating from different human tissues. Additionally, a variety of human tissues was examined for expression of PPK mRNA. 


\section{Results}

\section{Expression of PPK mRNA in Human Cell Lines and Tissues}

In order to examine whether tissues other than those reported as well as cultured cells express mRNA of plasma prekallikrein, a semi-nested RT-PCR was performed with total RNA of a variety of human tissues and cell lines. To confirm the identity of the amplicons, restriction fragments were prepared by incubating aliquots of the PCR mixtures with the endonuclease Sacl. The sizes of the PCR products and restriction fragments were determined by polyacrylamide gel electrophoresis. The silver stained gel of a typical experiment representing the result for RNA from HeLa cells is shown in Figure 1. For comparison samples of a PCR with leukocyte genomic DNA before and after digestion with $\mathrm{Sacl}$ (lanes 4 and 5) were also applied onto the gel. Figure 1 demonstrates that with RT-PCR of mRNA of HeLa cells a product of the size predicted for plasma prekallikrein mRNA (394 bp, R in lane 1; cf. Fig-

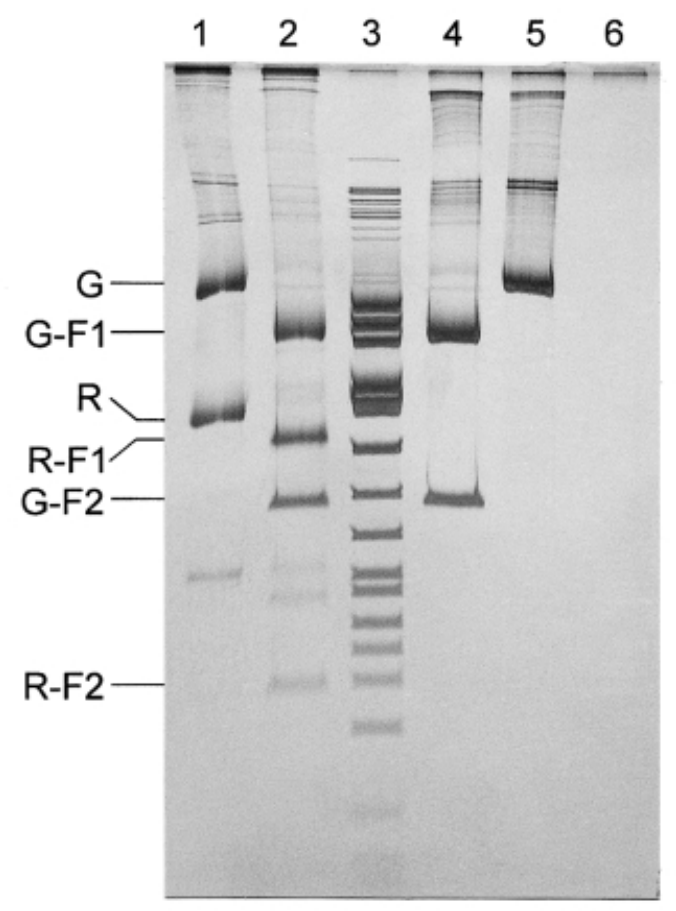

Fig. 1 Expression of Plasma Prekallikrein mRNA in HeLa Cells Demonstrated by Semi-Nested RT-PCR.

Total RNA was extracted from cultured HeLa cells and reverse transcribed using a specific primer for PPK. Semi-nested PCR was performed with the CDNA and genomic DNA. Aliquots of these reaction mixtures with and without Sacl digestion were subjected to PAGE. DNA bands were visualized by silver staining. Lane 1: cDNA; lane 2: cDNA after Sacl digestion; lane 3: DNA size standard; lane 4: genomic DNA after Sacl digestion; lane 5: genomic DNA; lane 6: negative control (semi-nested PCR was performed with a sample where in the reverse transcription step the RNA solution had been replaced by water). Designations of bands: G, G-F1, G-F2: amplicon of genomic DNA and its Sacl digestion fragments; R, R-F1, R-F2: amplicon of CDNA and its Sacl digestion products (for details see Figure 2 and Results). ure 2 ) is obtained, and that by digestion with Sacl fragments of the expected lengths are produced ( $312 b p+4 b$ and $78 b p+4 b, R-F 1$ and R-F2 in lane 2; the cleavage site of $\mathrm{Sacl}$ in the upper strand of the CDNA is located between bases 1195 and 1196, Figure 2). Figure 1 indicates that the RNA preparation was not absolutely free of genomic DNA since, in addition to the amplic on of the CDNA, a PCR product ( $G$ in lane $1, \approx 900 \mathrm{bp}$ ) and Sacl digestion fragments (G-F1, $\approx 663 b p+4 b$, and G-F2, $233 b p+4 b$, in lane 2 ) of the sizes expected for genomic DNA (lanes 4 and 5) were obtained.

Further proof that the amplicons $R$ and $G$ resulted indeed from mRNA and genomic DNA of P PK was gained by DNA sequence analysis of the PCR-products of HeLa cells using the forward primer hPK-29F. Except for some ambiguities, the readable sequences (Figure 2 ) were identical to the known sequences of PPK CDNA (880-1273 of GenBank accession number M 13143) and intron 8 (Kunapuli et al., 1995). The amplicon $\mathrm{G}$ must contain the three introns 8, 9 and 10 inserted after the positions 961, 1124 and 1237 of the cDNA sequence (Asakai et al., 1987; B eaubien et al., 1991; Kunapuli et al., 1995); the sequences of intron 8 and 10 have been elucidated previously (Kunapuli et al., 1995). The full-length intron 8 was found at the reported site (Figure 2). The exon-9/intron-9 junction is expected at position 367-368 of amplicon $G$ where, in fact, the sequence started to differ from the known cDNA sequence (Figure 2). As calculated from the sizes of amplicon $G$ (about 900 bp, cf. Figure 1), of introns 8 and 10 (158 and

Table 1 Expression of Plasma Prekallikrein mRNA in Fibroblast and Epithelial Cell Lines Derived from Various Human Tissues.

\begin{tabular}{|c|c|c|}
\hline Cell line or tissue & Comments & PPK mRNA \\
\hline WI 38 & Fibroblasts (lung) & + \\
\hline Colo 668 & Fibroblasts (colon) & + \\
\hline Decidua & $\begin{array}{l}\text { Fibroblasts } \\
\text { (primary culture) }\end{array}$ & + \\
\hline $\mathrm{HaCaT}$ & Keratinocytes & + \\
\hline HaCaT II-4RT & Keratinocytes & + \\
\hline PancTu & $\begin{array}{l}\text { Pancreatic tumor } \\
\text { (epithelial) }\end{array}$ & + \\
\hline BT 20 & $\begin{array}{l}\text { Mammary tumor } \\
\text { (epithelial) }\end{array}$ & + \\
\hline SW 480 & $\begin{array}{l}\text { Colon carcinoma } \\
\text { (epithelial) }\end{array}$ & + \\
\hline HT 29 & $\begin{array}{l}\text { Colon carcinoma } \\
\text { (epithelial) }\end{array}$ & + \\
\hline Kato III & $\begin{array}{l}\text { Stomach carcinoma } \\
\text { (epithelial) }\end{array}$ & + \\
\hline HeLa & $\begin{array}{l}\text { Cervix carcinoma } \\
\text { (epithelial) }\end{array}$ & + \\
\hline HUVEC & Primary culture & + \\
\hline Neutrophils & Freshly isolated & + \\
\hline Brain & Whole tissue & + \\
\hline Heart & Whole tissue & + \\
\hline Lung & Whole tissue & + \\
\hline Trachea & Whole tissue & + \\
\hline Liver & Whole tissue & + \\
\hline Kidney & Whole tissue & + \\
\hline
\end{tabular}




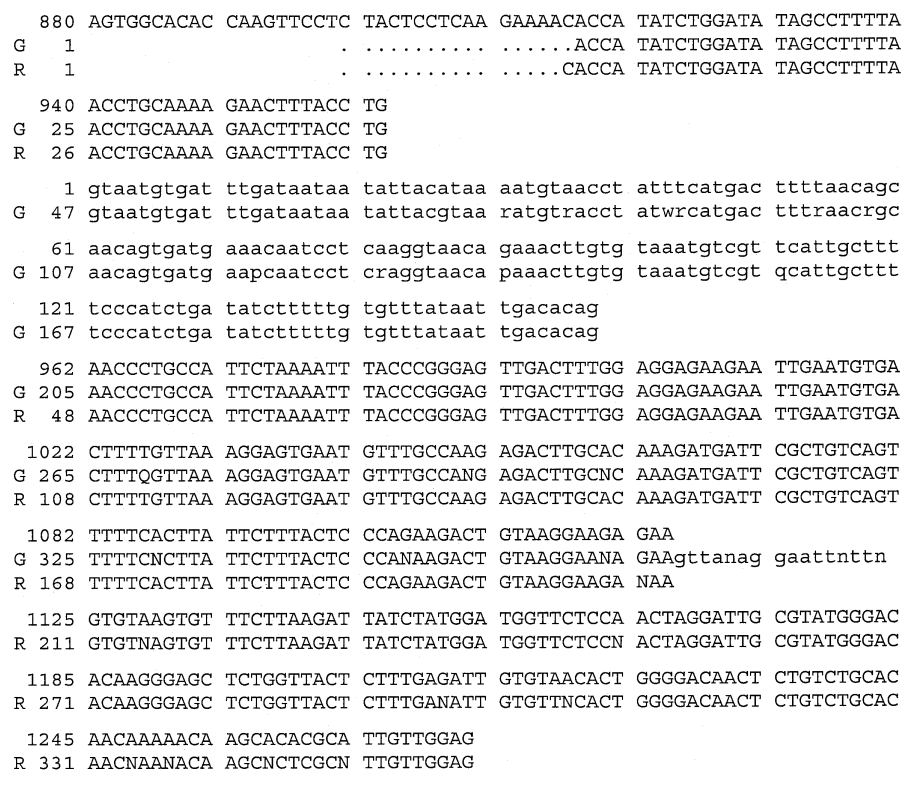

Fig. 2 Comparison of the Sequences Determined for Amplicons $G$ and R with Known Sequence Data.

The sequences determined for amplicons $G$ and $R$ (lines with prefixes $G$ and $R$, respectively) are aligned to the segment 880 - 1273 of the cDNA sequence of human plasma kallikrein (GenBank accession number M 13143) with the intron 8 (Kunapuli et al., 1995) inserted. Intron sequences are in lower case letters. The primer hPK-29F used for sequencing corresponds to bases $880-898$. The cleavage site for $\mathrm{Sacl}$ is between bases 1195 and 1196. Symbols for not clearly identified nucleotides: $P: A / G ; Q: C / T ; R: A / T ; W: G / T ; N: A / C / G / T$.

$155 \mathrm{bp}$, Kunapuli et al., 1995) and of the cDNA segment (394 bp), intron 9 has a length of about $200 \mathrm{bp}$. Intron 10 is not contained in the sequenced section of amplicon $\mathrm{G}$.

The same electrophoresis results as for HeLa cells, demonstrating the expression of plasma prekallikrein mRNA were obtained for total RNA from all cell lines investigated (Table 1) and from human liver, kidney, brain, heart, lung, trachea, HUVECs (human umbilical vein endothelial cells) and leukocytes.

\section{Discussion}

\section{Specificity of RT-PCR}

The primers for reverse transcription and PCR were selected in such a manner that amplicons of genomic DNA contained three introns and, therefore, were easily distinguishable from the $394 \mathrm{bp} \mathrm{PCR}$ product of CDNA by electrophoretic size determination. Indeed, when PCR was performed with genomic DNA a single product of about 900 bp was obtained (Figure 1 , lane 5 ), demonstrating that the amplicon of genomic DNA cannot be confused with that of CDNA and, in addition, that the human genome does not contain retropseudogenes of PPK that could give rise to PCR products of similar size as that of PPK CDNA.

Further confirmation that the amplicon resulted from mRNA was achieved by digestion with Sacl which produced fragments of the correct lengths of $312 \mathrm{bp}$ and 78 bp (Figure 1, lane 2). Like the undigested PCR products, these fragments were unequivocally distinguishable from those resulting from genomic DNA with predicted chain lengths of $\approx 663 \mathrm{bp}$ and $233 \mathrm{bp}$ (lanes 2 and 4 ). In addition, in the case of HeLa cells the identity of the cDNA amplicon was verified by sequence determination (Figure 2 ).

Partial DNA sequence determination of the $\approx 900 \mathrm{bp}$ $P C R$ product revealed that it indeed represented the amplicon of the respective PPK gene segment (Figure 2). The sequence was as expected for CDNA but with intron sequences inserted in the positions reported by Kunapuli et al. (1995), and as deduced from the homology of PPK with human factor XI (Asakai et al., 1987) and rat PPK (Beaubien et al., 1991). The $\approx 900 \mathrm{bp}$ band was observed in several RT-PCR experiments indicating some contamination of the RNA preparations with genomic DNA (cf. Figure 1, lane 1). However, since both the RT-PCR product of PPK $m R N A$ and its restriction fragments are unequivocally distinguishable from those of genomic DNA, no efforts were undertaken to achieve complete removal of genomic DNA from the RNA preparations. Taken together, the method of semi-nested RT-PCR combined with chain length estimation by PAGE and restriction fragment analysis provides a sensitive and specific means for the detection of PPK mRNA. It guarantees unambiguous results even in the presence of genomic DNA; further confirmation by DNA sequence analysis is not required.

\section{Expression of PPK mRNA in Nonhepatic Tissues and Cell Lines}

Plasma kallikrein is a serine proteinase that is present in blood as the inactive zymogen plasma prekallikrein. It is generally accepted that PPK is synthesized in hepatocytes and secreted into the blood where itcirculates mainly as a heterodimer complex with high molecular weight kininogen, and is available for participating in multiple 
physiological processes (see Introduction). Its synthesis in the liver was originally deduced from the fact that circulating levels of PPK were reduced in patients with liver cirrhoses (Colman and Wong, 1979). Direct evidence of hepatic PPK synthesis came from immunocytochemical studies using confocal laser scanning microscopy which demonstrated PPK in hepatocytes (Henderson et al., 1992). Recently, Ciechanowicz et al. (1993) and our group (Hermann et al., 1996) provided evidence for extrahepatic synthesis of PPK: by employing RT-PCR, expression of PPK mRNA was detected in human liver, kidney, adrenal gland and placenta. The aim of the present study was to clarify whether PPK mRNA is expressed in tissues other than the liver and in tissue-specific cells, and to find a model for studying extrahepatic PPK synthesis and its regulation. We therefore analyzed RNA from various tissues, from leukocytes, from primary culture of human umbilical vein endothelial cells and from cell lines of fibroblasts and epithelial cells. We found that PPK MRNA is present in all of them (Table 1). The presence of PPK mRNA in the ubiquitously occurring fibroblasts, leukocytes and endothelial cells may suggest that these cell types are the only ones expressing PPK mRNA extrahepatically. However, the PPK gene is transcribed also in epithelial cell lines originating from different organs (Table 1). Thus, the results indicate that expression of PPK mRNA and assumingly also of the protein takes place not only in ubiquitous cells but also in tissue-specific epithelial cells throughout the organism. The final answer to the question as to which of the cells in the various tissues express PPK mRNA will be arrived at from in situ hybridization or in situ RT-PCR studies.

\section{Extrahepatic Synthesis of PPK}

Expression of a mRNA provides strong indication, but does not necessarily prove synthesis of the respective protein. Synthesis of PPK has until now been shown only in the liver by Henderson et al. (1992) who demonstrated immunoreactive PPK in isolated human hepatocytes by confocal laser scanning microscopy and in sections of liver by light microscopy. Seidah et al. (1988) isolated plasma kallikrein from human pituitary gland, however, they could not exclude the possibility that the enzyme resulted from blood or the extravascular bed. Even though no unambiguous evidence of extrahepatic synthesis of PPK has been presented, the transcription of the gene in various tissues and cell lines demonstrates that extrahepatic synthesis of PPK is possible, but final proof will have to come from studies at the protein level.

\section{Possible Physiological Functions of Extrahepatically Synthesized PPK}

The physiological function of PPK synthesized in extrahepatic tissues can only be speculated upon. It may contribute to the PPK pool in blood plasma or cause local activation of various proenzymes (cf. Introduction). Also, concluding from in vitro studies, local processing of pro- hormones seems possible (Seidah et al., 1988). We favor the idea that PPK synthesized in extrahepatic tissues may function as a local kininogenase, acting similar to glandular (tissue)kallikrein in an autocrine- or paracrine-like manner. Glandular kallikrein is completely different from PK (Bhoola et al., 1992); the two enzymes have in common that they liberate kinin from kininogens, PK releases bradykinin, glandular kallikrein lysyl-bradykinin. Consistent with this hypothesis are our studies on mRNA expression of other components of the kallikrein-kinin system which demonstrate that the genes of high molecular weight kininogen (manuscript submitted) and FXII (unpublished results) are transcribed also in many nonhepatic tissues and cells. Thus it appears reasonable to assume that many tissues are furnished with a complete plasma kallikrein-kinin system that can become activated and exert local effects.

Our results confirm the reports of Ciechanowicz et al. (1993) and Hermann et al. (1996) and demonstrate that the PPK gene is transcribed in an even larger variety of tissues and cells than reported by these authors. Inferring from the results with epithelial cell lines, not only ubiquitously occurring cells are the origin of PPK mRNA but also tissuespecific cells. The next steps will be to verify extrahepatic PPK protein synthesis by immunocytochemical methods and to perform studies on cell lines with respect to PPK synthesis and its regulation.

\section{Materials and Methods}

\section{Cell Lines and Cell Culture Conditions}

Human keratinocyte cell lines $\mathrm{HaCaT}$, a spontaneously immortalized aneuploid cell line (Boukamp et al., 1988) and HaCaT II$4 \mathrm{RT}$, derived from $\mathrm{HaCaT}$ by transfection with the c-Ha-ras (EJ) oncogene (Boukamp et al., 1990) were kind gifts of Dr. N. E. Fusenig (German Cancer Research Center, Heidelberg). PancTu cells (Kalthoff et al., 1993) were kindly provided by Dr. K. Pantel (Institute of Immunology, University of Munich), primary cultures of decidua cells by Dr. J . Rehbock (Hospital of Gynecology, University of Munich) and primary cultures of human umbilical vein endothelial cells (HUVEC) and leukocytes by Dr. I. Müller (our institute). WI 38, SW 480, Kato III, BT 20 and HT 29 were from American Type Culture Collection, Colo 668 cells from the German Collection of Microorganisms and Cell Culture (Braunschweig, Germany), HeLa cells from EACC, Salisbury, UK.

Cells were cultured at $37{ }^{\circ} \mathrm{C}$ in a humidified atmosphere of $5 \%$ $\mathrm{CO}_{2}$ and $95 \%$ air. $\mathrm{HaCaT}, \mathrm{HaCaT}$ II and WI 38 were grown in DMEM medium containing $1 \mathrm{~g} / \mathrm{l}$ glucose (PAA, Cölbe, Germany), supplemented with $0.35 \mathrm{~g} / \mathrm{l}$ L-glutamine, $0.05 \mathrm{~g} / \mathrm{l}$ gentamicin sulfate (Biowhittaker, Boehringer Ingelheim, Germany) and 10\% fetal calf serum (PAA, Cölbe, Germany). Colo 668, decidua, BT 20, HT 29, SW 480 and PancTu cells were grown in RPMI medium (Biowhittacker), supplemented with $0.35 \mathrm{~g} / \mathrm{l} \mathrm{L-glutamine,} 100 \mathrm{U} /$ ml penicillin, $0.1 \mathrm{~g} / \mathrm{lstreptomycin} \mathrm{(Sigma,} \mathrm{Deisenhofen,} \mathrm{Germany)}$ and $10 \%$ fetal calf serum (PAA).

After reaching confluence cells were harvested by incubation with $0.5 \mathrm{~g} / \mathrm{l}$ trypsin and $0.2 \mathrm{~g} / \mathrm{IEDTA}$ (Sigma) for $10 \mathrm{~min}$. The proteolytic activity of trypsin was stopped by the addition of medium containing fetal calf serum. The cells were isolated from the suspensions (centrifugation at $200 \mathrm{~g}$ for $10 \mathrm{~min}$ ) and washed twice 
with phosphate buffered saline. Aliquots of about $10^{7}$ cells were stored at $-70^{\circ} \mathrm{C}$ in RNase-free plastic tubes until use.

\section{RNA Preparation}

Total RNA was extracted from cultured cells and leukocytes by using the method described by Chomzynski and Sacchi (1987). B riefly, about $10^{7}$ cells were lysed with $500 \mu$ I nucleic acid extraction buffer ( $4 \mathrm{M}$ guanidine isothiocyanate, $5 \mathrm{~g} / \mathrm{l} \mathrm{N}$-laurylsarcosine sodium salt, $0.1 \mathrm{~m} 2$-mercaptoethanol, $25 \mathrm{~mm}$ sodium citrate, $\mathrm{pH}$ 7). $50 \mu \mathrm{l}$ of $2 \mathrm{~m}$ sodium acetate $\mathrm{pH} 5.2$ were added to the homogenates. The suspension was extracted with $500 \mu$ l pheno and $100 \mu \mathrm{l}$ of a chloroform/isoamyl alcohol mixture $(49: 1, \mathrm{v} / \mathrm{v})$ and centrifuged at $13000 \mathrm{~g}$. The RNA dissolved in the aqueous phase was precipitated with ethanol and suspended in diethylpyrocarbonate-treated water. The isolated RNA was quantified spectrophotometrically at $260 \mathrm{~nm}$. A negative control was obtained by performing the whole procedure without adding cells. Total RNA from human liver, kidney, brain, heart, lung, and trachea was purchased from Clontech Laboratories (Paolo Alto, USA; catalog number K4000-1).

\section{Reverse Transcription and PCR}

Primers for semi-nested RT-PCR were selected from the CDNA sequence of human PPK (GenBank accession number M 13143) taking into consideration the partially known exon-intron organization (Kunapuli et al., 1995) that the PCR product included three exon-exon transitions. All primers were synthesized by MWGBiotech (Ebersberg, Germany). The primers used were: hPK-29F, 5'-AGTG G CACAC CAAGT TCCT-3' (880- 898, in exon 8), hPK422R, 5'-CTCCA ACAAT GCGTG TGCT-3' (1273-1255, in exon 11), hPK-486R, 5'-TGAGC TGTCA GCTTC ACCT-3' (13371319 , in exon 11). The quality of mRNA and CDNA preparations was validated by RT-PCR amplifying a segment of the ribosomal protein RPS4X (GenBank accession number M 58458) using the forward primer RPX-1, 5'-TTCCT TGCCT AACGC AGC-3', and the reverse primer RPX-2, 5'-GATCT CACAT GTCAC CCA-3'.

CDNA of plasma prekallikrein and RPS $4 \mathrm{X}$ was synthesized using a First Strand cDNA Synthesis Kit (Pharmacia, Freiburg, Germany). $1 \mu \mathrm{g}$ of total RNA or a corresponding volume of the negative control was incubated with $1 \mu \mathrm{l}$ of $200 \mathrm{~mm}$ dithiothreitol, $50 \mathrm{ng}$ of the outer reverse primer $\mathrm{hPK}-486 \mathrm{R}, 50 \mathrm{ng}$ of primer RPX-2 and RNase-free water in a final volume of $10 \mu l$. The incubation was performed at $65^{\circ} \mathrm{C}$ for $10 \mathrm{~min}$ and then the mixture was placed on ice. $5 \mu$ l of the 'Bulk First Strand Reaction Mix' (Pharmacia, Freiburg, Germany), containing murine reverse transcriptase, RNAguard, bovine serum albumin and deoxynucleotide triphosphates, were added and the mixture incubated at $37^{\circ} \mathrm{C}$ for $2 \mathrm{~h}$.

The first PCR was performed with $1 \mu$ l of CDNA synthesis reaction mixtures, of the negative control, and of genomic DNA. To these samples $5 \mu$ l of Taq DNA polymerase buffer ( $100 \mathrm{~mm}$ Tris$\mathrm{HCl} \mathrm{pH} \mathrm{9.0,500} \mathrm{mM} \mathrm{KCl,} 15 \mathrm{~mm} \mathrm{M} \mathrm{gCl} 2,1 \mathrm{~g} / \mathrm{l}$ gelatin, $1 \%$ Triton $X-$ 100), $1 \mu$ l of $20 \mathrm{~mm}$ dNTP solution (Pharmacia, Freiburg, Germany), $50 \mathrm{ng}$ of the outer reverse primer (hPK-486 R) and $50 \mathrm{ng}$ of the forward primer (hPK-29F), autoclaved water up to $50 \mu \mathrm{l}$ and 0.5 units of Taq DNA polymerase (Boehringer Mannheim, Germany) were added. 20 cycles of PCR amplification were performed each one consisting of a denaturation step at $92^{\circ} \mathrm{C}$ for $30 \mathrm{~s}$, an annealing step at $52^{\circ} \mathrm{C}$ for $30 \mathrm{~s}$ and an elongation step at $72^{\circ} \mathrm{C}$ for $30 \mathrm{~s}$

The second PCR with the forward primer hPK-29F and the inner reverse primer $h P K-422 R$ was performed with $1 \mu$ l of the $1: 10$ diluted reaction mixture of the first $P C R .35$ cycles were run with the profile described above. PCR for RPS4X CDNA amplification was performed only in the second PCR using the primers RPX-1 and RPX-2.

\section{Restriction Analysis}

Aliquots of $4 \mu$ l of the PCR mixtures of CDNA and genomic DNA were incubated at $37^{\circ} \mathrm{C}$ for $2 \mathrm{~h}$ with $7.5 \mathrm{U}$ of the restriction enzyme Sacl (Boehringer Mannheim, Germany) and $0.4 \mu \mathrm{l}$ cleavage buffer. A third aliquot remained undigested and was diluted to the same volume.

\section{Size Determination by PAGE}

For size determination the PCR products, restriction fragments and a DNA size marker (G1751, Promega, Mannheim, Germany) were subjected to PAGE on a $14.5 \%$ acrylamide gel in $44.5 \mathrm{~mm}$ Tris, $44.5 \mathrm{~mm}$ boric acid, $1.0 \mathrm{~mm}$ EDTA, pH 8.0. DNA bands were visualized by silver staining (Riesner et al., 1989).

\section{Sequence Analysis}

PCR products were purified by agarose gel electrophoresis and subsequent isolation of the respective band from the gel using a QIAquick gel extraction kit (Qiagen, Hilden, Germany). Nucleotide sequences were analyzed by the dideoxynucleotide chain-termination method using the Dye Terminator Cycle Sequencing Ready Reaction Kit (Perkin-Elmer, Weiterstadt, Germany) and an ABI PRISM 377 DNA sequencer (Perkin-Elmer).

\section{Acknowledgements}

We are very grateful to Dr. G. Pantel, Munich, Dr. J. Rehbock, Munich, Dr. I. Müller and Prof. N. E. Fusenig, Heidelberg, for providing primary cultures and cell lines. We thank Mrs. H. Hinz for performing DNA sequence analyses.

\section{References}

Asakai, R., Davie, E.W., and Chung, D.W. (1987). Organization of the gene for human factor XI. B iochemistry 26, 7221- 7228.

Beaubien, G., Rosinski-Chupin, I., Mattei, M.G., Mbikay, M., Chrétien, M., and Seidah, N.G. (1991). Gene structure and chromosomal localization of plasma kallikrein. Biochemistry 30, $1628-1635$.

Bhoola, K.D., Figueroa, C.D., and Worthy, K. (1992). Bioregulation of kinins: kallikreins, kininogens, and kininases. Pharmacol. Rev. 44, 1- 80.

Boukamp, P., Petrussevska, R.T., B reitkreutz, D., Hornung, J ., Markham, A., and Fusenig, N.E. (1988). Normal keratinization in a spontaneously immortalized aneuploid human keratinocyte cell line. J. Cell. Biol. 106, $761-771$.

Boukamp, P., Stanbridge, E.J., Foo, D.Y., Cerutti, P.A., and Fusenig, N.E. (1990). C-Ha-ras oncogene expression in immortalized human keratinocytes ( $\mathrm{HaCaT}$ ) alters growth in vivo but lacks correlation with malignancy. Cancer Res. 50, 2840 2847.

Chomczynsky, P., and Sacchi, N. (1987). Single-step method of RNA isolation by acid guanidinium thiocyanate-phenol-chloroform extraction. Anal. Biochem. 162, $156-159$.

Ciechanowicz, A., Bader, M., Wagner, J ., and Ganten, D. (1993). Extra-hepatic transcription of plasma prekallikrein gene in human and rat tissues. Biochem. Biophys. Res. Commun. 197, $1370-1376$

Colman, R.W., and Wong, P.Y. (1979). Kallikrein-kinin system in pathologic conditions. In: Handbook of Experimental Pharmacology. E. G. Erdös, ed. (Heidelberg, New York: Springer), pp. $569-607$. 
DiScipio, R.G. (1982). The activation of the alternative pathway C 3 convertase by human plasma kallikrein. Immunology 45 , 587- 595.

Ghebrehiwet, B., Silverberg, M., and Kaplan, A.P. (1981). Activation of the classical pathway of complement by Hageman factor fragment. J . Exp. Med. 153, 665-676.

Ghebrehiwet, B., Randazzo, B.P., Dunn, J .T., Silverberg, M., and Kaplan, A.P. (1983). Mechanisms of activation of the classical pathway of complement by Hageman factor fragment. J. Clin. Invest. 71, $1450-1456$.

Hauert, J., Nicoloso, G., Schleuning, W.D., Bachmann, F., and Schapira, M. (1989). Plasminogen activators in dextran sulfateactivated euglobulin fractions: a molecular analysis of factor XII- and prekallikrein-dependent fibrinolysis. Blood 73, 994 999.

Henderson, L.M., Figueroa, C.D., Müller-Esterl, W., Stain, A., and Bhoola, K.D. (1992). Immunovisualisation of plasma prekallikrein and $\mathrm{H}$-kininogen on human neutrophils and in human hepatocytes. Agents Actions Suppl. 38(Pt.1), 590 - 594.

Hermann, A., Buchinger, P., Somlev, B., and Rehbock, J . (1996). High and low molecular weight kininogen and plasma prekallikrein/plasma kallikrein in villous capillaries of human term placenta. Placenta 17, $223-230$.

Ichinose, A., Fujikawa, K., and Suyama, T. (1986). The activation of pro-urokinase by plasma kallikrein and its inactivation by thrombin. J . Biol. Chem. 261, 3486- 3489.

Kalthoff, H., Schmiegel, W., Roeder, C., Kasche, D., Schmidt, A., Lauer, G., Thiele, H. G., Honold, G., Pantel, K., Riethmüller, G., Scherer, E., Maurer, J., Maacke, H., and Depperts, W. (1993). P53 and K-RAS alterations in pancreatic epithelial cell lesions. Oncogene 8, 289-298.

Kunapuli, S.P., Stark, P., Rick, L., and Colman, R.W. (1995). Determination of gene structure by intron trapping using polymerase chain reaction: application to the human plasma prekallikrein gene. DNA Cell Biol. 14, 343- 347

Mandle, R.J ., Colman, R.W., and Kaplan, A.P. (1976). Identification of prekallikrein and high molecular weight kininogen as a complex in human plasma. Proc. Natl. Acad. Sci. USA 73, 4179- 4183 .

Mandle, R.J ., and Kaplan, A.P. (1977). Hageman factor substrates. II. Human plasma prekallikrein. Mechanism of activation by Hageman factor and participation in Hageman factor dependent fibrinolysis. J . Biol. Chem. 252, 6097-6104.

Riesner, D., Steger, G., Zimmat, R., Owens, R.A., Wagenhöfer, M., Hillen, W., Vollbach, S., and Henco, K. (1989). Temperaturegradient gel electrophoresis of nucleic acids: analysis of conformational transitions, sequence variations, and proteinnucleic acid interactions. Electrophoresis 10, 377- 389.

Schapira, M., Despland, E., Scott, C.F., Boxer, L.A., and Colman, R.W. (1982). Purified human plasma kallikrein aggregates human blood neutrophils. J. Clin. Invest. 69, 1199- 1202.

Schapira, M., Scott, C.F., Boxer, L.A., and Colman, R.W. (1983). Activation of human polymorphonuclear leukocytes by purified human plasma kallikrein. Adv. Exp. Med. Biol. 156, 747- 753.

Seidah, N.G., Paquin, J ., Hamelin, J ., Benjannet, S., and Chrétien, M. (1988). Structural and immunological homology of human and porcine pituitary and plasma IRCM-serine protease 1 to plasma kallikrein: marked selectivity for pairs of basic residues suggests a widespread role in pro-hormone and pro-enzyme processing. Biochimie 70, 33-46.

van der Graaf, F., Tans, G., Bouma, B.N., and Griffin, J .H. (1982). Isolation and functional properties of the heavy and light chains of human plasma kallikrein. J. B iol. Chem. 257, 14300 - 14305.

Wachtfogel, Y.T., Kucich, U., J ames, H.L., Scott, C.F., Schapira, M., Zimmerman, M., Cohen, A.B., and Colman, R.W. (1983). Human plasma kallikrein releases neutrophil elastase during blood coagulation. J . Clin. Invest. 72, 1672 - 1677.

Wachtfogel, Y.T., Pixley, R.A., Kucich, U., Abrams, W., Weinbaum, G., Schapira, M., and Colman, R.W. (1986). Purified plasma factor XIla aggregates human neutrophils and causes degranulation. Blood 67, 1731 - 1737.

Received February 22,1999; accepted May 12,1999 